ISSN: 0213-2052 - eISSN: 2530-4100

DOI: https://doi.org/10.14201/shha202139209236

\title{
LA PRESENCIA FEMENINA EN LA REVUELTA DE ESPARTACO: SU RECEPCIÓN CINEMATOGRÁFICA Y TELEVISIVA
}

\section{The Female Presence in the Spartacus Revolt: Its Cinematographic and Television Reception}

\author{
Óscar LAPEÑA MARCHENA \\ Universidad de Cádiz \\ oscar.lapenia@uca.es
}

Fecha de recepción: 3-11-2020 Fecha de aceptación: 10-2-2021

ORCID: https://orcid.org/0000-0001-5165-8118

RESUMEN: Son escasos los testimonios literarios que refieren la presencia de mujeres en la revuelta servil de Espartaco, ya sea como participantes de la misma o como romanas que padecen los efectos de la rebelión. Suelen estar asociadas a la presencia de cultos religiosos, destacando el episodio del sueño de Espartaco interpretado por su compañera conocedora de los cultos dionisíacos. En la rescritura que el cine y la televisión ha realizado del episodio, Espartaco se ha convertido en un trofeo sentimental y sexual por el que compiten por igual esclavas y romanas.

Palabras clave: Espartaco; revuelta; cine; mujer.

ABSTRACT: Literary testimonies that refer to the presence of women in the servile revolt of Spartacus are scarce, either as participants in it or as Romans who suffer the effects of the rebellion. They are usually associated with the presence of religious cults, highlighting the episode of Spartacus' dream interpreted by his companion who knows the Dionysian cults. In the film and television rewriting of the episode, Spartacus has become a 
sentimental and sexual trophy for which female slaves and Roman women alike compete.

Keywords: Spartacus; Revolt; Cinema; Woman.

Los testimonios literarios más antiguos que han llegado hasta nosotros que abordan la revuelta de Espartaco (73-71 a. C.) fueron escritos por Cicerón pocos meses después del fin de los acontecimientos. Estas referencias dan comienzo a un corpus literario que abarca más de una treintena de testimonios - tanto griegos como romanos-, que se extienden hasta el siglo IV d. C. Utilizando a todas esas menciones —algunas extensas, otras breves, apenas una frase o un nombre-, se pueden reconstruir en buena medida los diferentes episodios y personajes que dan vida a la revuelta ${ }^{1}$.

El mayor porcentaje de información se ocupa de cuestiones militares y políticas. A partir de ellas se puede discutir si el episodio iniciado en el ludus de Capua fue un simple episodio de orden público —en especial en sus orígenes — $^{2}$ o si, por el contrario, Roma llegó a estar ante una amenaza comparable a la representada por Aníbal durante la II Guerra Púnica ${ }^{3}$. Los diferentes testimonios también permiten realizar una reconstrucción de cómo gestionó el Senado romano la revuelta, desde el nombramiento de mandos poco preparados, pasando por el reclutamiento apresurado de tropas, hasta la posterior entrada en escena de personajes relevantes en la política de Roma, como Craso o Pompeyo ${ }^{4}$.

A partir del citado elenco de autores griegos y romanos, ha ido tomando forma una extensa tradición bibliográfica posterior que se ha ocupado principalmente de asuntos como la composición de las fuerzas rebeldes, de sus diferencias internas, sus objetivos y, especialmente, de si la revuelta de Espartaco tuvo un indiscutible carácter servil (como las dos de Sicilia), o de si se trató de una manifestación más de la hostilidad de algunas zonas de Italia hacia Roma; un malestar que estalló años atrás en la Guerra Social (91-83 a. C.), en el conflicto contra las ciudades aliadas

1. Diferentes visiones sobre la revuelta de Espartaco se pueden encontrar en: Guarino, Spartaco. Spartacus, Symposium. Orena, Rivolta e rivoluzione. Bradley, Slavery and rebellion. Wiedemann, Emperors. Lapeña, El mito. Strauss, La Guerra. Urbainczyk, Spartaco. Schiavone, Spartaco.

2. Cicerón, en una de sus invectivas contra Antonio, ya identificó a Espartaco con un latro, un simple bandido (Phil. IV, 6, 15).

3. Hor. Epod. XVI, 5. Sen. Cont. VII, 2, 7. Eutr. VI, 7, 2. Claud. Bell. Get. 154 y ss. Oros. Hist. V, 24, 5.

4. Posadas, «La recluta», 61-72. 
de Italia, que demandaban mayores derechos políticos a Roma. Esta afirmación deriva de la presencia de diversos elementos libres en las filas rebeldes, así como en el escenario y la propia cronología de algunos de los episodios de la rebelión de Espartaco5.

Pero tanto las fuentes grecolatinas como la tradición bibliográfica posterior presentan significativas lagunas e interrogantes todavía abiertos, como pueden ser el verdadero detonante de los hechos (¿malas condiciones y malos tratos en el ludus de Capua como sucede en la I revuelta siciliana?), los objetivos reales de los sublevados, las relaciones entre los diferentes líderes rebeldes ${ }^{6}$, o la presencia de las mujeres en la revuelta, tanto en el bando romano como en las filas sublevadas. El silencio que oculta la huella femenina no debe extrañar, ya que los testimonios literarios del mundo clásico conservados han sido elaborados de manera abrumadora por mentes y manos masculinas pertenecientes a la elite social y económica. Que, además, se han ocupado de un modo casi exclusivo de cuestiones políticas, militares y religiosas; en sus páginas la figura femenina aparece, sobre todo, por su cercanía y vinculación con los círculos de poder, conforme más se desciende por la escala social, menor presencia y peso tienen en los testimonios literarios. Sería francamente paradójico pretender que esos autores escribieran sobre mujeres esclavas y campesinas, un argumento sobre el que carecen de todo conocimiento.

Desde el siglo XVIII se ha ido creando en la cultura occidental una imagen de Espartaco asociada siempre a mensajes e ideas contemporáneos; el Espartaco de las esculturas neoclásicas y decimonónicas lo convertían en un adalid de la lucha por la libertad ilustrada ${ }^{7}$; cuando el actor de Filadelfia Edwin Forrest recitaba en los teatros norteamericanos la obra The Gladiator (Robert Montgomery Bird, 1831), Espartaco asumía los rasgos físicos y el mensaje político de Abraham Lincoln. Un fenómeno parecido se produce unos años más tarde cuando en 1874 — solo tres después de la unificación italiana-, el periodista y antiguo soldado garibaldino Raffaele Giovagnoli publica la novela Spartaco, en cuyas páginas el gladiador tracio abandona muchas de sus aspiraciones rebeldes para luchar por la paz y la justicia en Roma, como si Giuseppe Garibaldi hubiera

5. Rubinsohn, «Was the bellum», 290-299.

6. Salustio (Hist. III, 90), Cicerón (Att. VI, 2, 8, 9), Lucano (II, 554) y Apiano (B. C. I, 116-120) hacen de Espartaco el líder indiscutible de la revuelta; por su parte, los testimonios de Tito Livio (Per. XCV, 2; XCVI, 1; XCVII, 1), Eutropio (VI, 7, 2), Orosio (Hist. V, 24, 1), Agustín de Hipona (C. D. III, 26) y Sinesio de Cirene (Real. 24 a) sitúan a Espartaco, Crixo, Casto y Gánico en un plano de igualdad.

7. Como, por ejemplo, Spartacus brisan ses chaines, de Denis Foyatier (1830), o Le serment de Spartacus, de Louis Ernest Barris (1871). 
emprendido un viaje en el tiempo hacia el pasado ${ }^{8}$. A partir de un comentario aislado en una carta fechada el 27 de febrero de 1861 dirigida por Carlos Marx a Federico Engels en donde se elogiaba a Espartaco9, va a iniciarse una corriente bibliográfica especialmente fértil en la Unión Soviética y en países aliados que convierte a Espartaco en el indiscutible líder de la revolución servil en Roma, en un proceso histórico que anticipa la posterior revolución proletaria.

La dinámica de continua reelaboración del personaje adquiere una nueva dimensión desde finales del siglo XIX e inicio del XX con la extensión por todo Occidente del cinematógrafo. A partir de ese momento, primero en las pantallas de los cines y luego en las de las televisiones y otros formatos de reproducción audiovisual, ha ido tomando forma un novedoso y poliédrico Espartaco, heredero de la tradición literaria, artística y política anterior, pero capaz también de aportar elementos novedosos.

Podemos identificar casi una cuarentena de producciones (cinematográficas, televisivas o destinadas directamente al mercado del vídeo doméstico), en donde encontramos a Espartaco, ya sea como protagonista, secundario o actuando como simple reclamo. Un número no muy elevado si comparamos las oportunidades en que otras figuras del Mundo Antiguo lo han hecho; muy lejos, cuantitativamente, de nombres como Jesucristo, Cleopatra, Alejandro Magno, Julio César, Nerón, o el personaje colectivo de las momias egipcias. Y lo ha hecho, además, en formatos narrativos y productivos muy diversos: el kolossal italiano anterior a la I Guerra Mundial, el cine histórico, la gran producción - epic- de Hollywood, el péplum, el terror, el ballet filmado, el cine para adultos o el folletín televisivo.

En este trabajo pretendemos abordar tres aspectos fundamentales: en primer lugar, queremos realizar un análisis acerca de la presencia de mujeres en la revuelta de Espartaco según los testimonios grecolatinos. Un segundo apartado se dedicará, de manera concisa, a la presencia de Espartaco en el cine y la televisión. Para concluir centrándonos en la presencia femenina en esas producciones.

La escasez de referencias a mujeres en la revuelta de Espartaco coincide con la casi ausencia a menciones en otras revueltas serviles que, en mayor o menor grado, amenazaron a Roma. La primera de esta breve serie de alusiones se refiere al intento por parte de un grupo de esclavos que, en el año 419 a. C., planean prender fuego a Roma, tomar el Capitolio, liberar a los esclavos que hubiera en la ciudad y hacerse con los bienes

8. Russo, "Lo Spartaco», 74 .

9. Guarino, Spartaco, 121. 
y las mujeres de los ciudadanos romanos ${ }^{10}$. Se trata de una mención concisa, pero que sirve para recordar que la presencia de mujeres se encuentra también entre la población romana, y que, en muchas ocasiones, los esclavos sublevados solo pretendían invertir la situación social y económica: devolver la violencia que recibían de modo cotidiano y hacerse con las propiedades de sus dueños.

Semejante parquedad de información disponemos para el siguiente episodio que tiene lugar a finales del siglo II a. C., y que se desarrolla en la Campania, donde en el año 103 Titus Vettius, un ciudadano romano, armó a cuatrocientos esclavos y se encaminó hacia Capua; una traición interna evitó la amenaza y lo empujó al suicidio. En las fuentes romanas el motivo de la traición entre esclavos o bandidos para explicar el final de los episodios de violencia es una constante. Los escasos testimonios sugieren que detrás del modo de actuar de Vettius estaban las deudas y el amor que sentía hacia una esclava ${ }^{11}$. Puede llamar la atención la referencia a los sentimientos del romano hacia su esclava que, creemos, no deben ser vistos con ojos y juicio contemporáneos. Más bien hemos de suponer que los romanos de la época, al conocer la historia, pensarían que Titus Vettius era un hombre del que había que desconfiar ya que se dejaba llevar por un comportamiento alejado de los parámetros del buen romano, y que se concretaba en ese afán descontrolado por el juego, de ahí las deudas, y por encapricharse de una esclava.

Acabamos este breve apartado retrocediendo unos años hasta situarnos en los inicios de la I revuelta servil de Sicilia (135-132 a. C). Como detonante de los acontecimientos se señalan los malos tratos y las vejaciones sufridas por los esclavos de la pareja de propietarios formada por Damófilo y su esposa Megallis. El testimonio de Diodoro de Sicilia indica que Megallis fue torturada hasta la muerte por las mismas esclavas que antes tuvieron que soportar sus caprichos, humillaciones y violencia ${ }^{12}$. Su destino contrasta con el que le aguarda a una de las hijas de la pareja, quien fue perdonada por los esclavos debido al trato más humano que les dispensaba ${ }^{13}$. Hemos de suponer que el perdón consistió en dejarla con vida, pero que acto seguido sería convertida en esclava por sus antiguos sirvientes. Estos hechos nos vuelven a recordar dos ideas básicas acerca de la esclavitud en Roma y sus formas de resistencia. La primera es que una de las bases de la institución de la esclavitud es la violencia, siempre

10. Liv. IV, 45, 1-2. Per. IV. Dion Hal. XII, frag. 6, 6. Capozza, Movimenti servili, 67-72.

11. D. S. II, 2, 6; XXXVI, 2, 1 s. Sánchez León, Revueltas, 38.

12. D. S. XXXIV/XXXV, 2, 15; XXXVI, 3, 4.

13. D. S. XXXXIV/XXXV, 2, 14-14. 
presente en la relación que se establece entre propietarios y esclavos; violencia que está siempre presente y parece aceptada por todos salvo que se superen ciertos límites especialmente aberrantes. Y la segunda cuestión es que la principal aspiración de los esclavos es dejar de serlo, convertirse en propietarios de bienes, riquezas y, por supuesto, de otros esclavos.

Centrándonos en la revuelta de Espartaco, las alusiones a la presencia de mujeres se limitan a tres autores: Salustio, Plutarco y Orosio. El primero, romano, escribe no mucho después de los acontecimientos; Plutarco es un griego del siglo II d. C. que ha dejado uno de los retratos más positivos del tracio. Y, por último, Paulo Orosio se sitúa en el siglo IV d. C. y aborda su historia de Roma desde una perspectiva cristiana.

En las Historias de Salustio hay dos alusiones a la presencia de la mujer en el transcurso de los hechos. El primero de los fragmentos ${ }^{14}$ hace referencia a los daños materiales y humanos causados por la revuelta; en concreto, alude a la violación de mujeres romanas por parte de los rebeldes. Veleyo Patérculo ${ }^{15}$ y Claudiano ${ }^{16}$ también consignan estos daños, pero sin ofrecer más detalles. Esta referencia subraya el hecho de que la revuelta no fue percibida por la población romana como un peligro grave pero ABSTRACTo (sensación que, en ocasiones, trasladan algunos testimonios, sobre todo los que se limitan a equiparar a Espartaco con Aníbal sin indicar nada más), sino que, por el contrario, había estado sometida a constantes muestras de violencia y daño real.

Paradójicamente, la violencia de los rebeldes contra la población romana ha sido uno de los aspectos que más se ha minimizado, cuando no directamente obviado, en la posterior recepción cinematográfica del episodio. La mayoría de las producciones cinematográficas y televisivas realizan un tratamiento muy similar de la revuelta, tratando, principalmente, el origen y estallido de la misma, la fuga al Vesubio y primeros combates con fuerzas romanas, organización de los rebeldes, intrigas en el bando romano, algunos encuentros armados más hasta la derrota final, todo ello aderezado con elementos de drama, romance y erotismo. Los efectos de la violencia de los sublevados sobre la población civil no encuentran sitio en la pantalla. Paradigmático resulta el caso de Spartacus (S. Kubrick, 1960), tal vez el título más influyente a la hora de crear el Espartaco cinematográfico ${ }^{17}$; allí, y debido a los enfrentamientos entre

14. Sall. Hist. III, 98 B.

15. His. II, 30, 5.

16. Bell. Get. 156

17. Sobre la génesis del film y las desavenencias internas: Cooper, «Who killed», 18. Cooper, «Dalton Trumbo», 34-38. Douglas, Yo soy. Lapeña, «Spartacus». 
el nuevo director del proyecto - Stanley Kubrick-, el autor del libro que dio origen a todo - Howard Fast-, el guionista - Dalton Trumbo- y el productor y actor protagonista —Kirk Douglas-, se acabó ofreciendo una imagen de la revuelta con un alto componente religioso, en donde los esclavos vagan por Italia como el pueblo judío tras la salida de Egipto, en donde hay algún intento por abandonar la península itálica, pero que apenas muestra los daños provocados: unos pocos planos ofrecen imágenes de los rebeldes a caballo al anochecer dispuestos a atacar un campamento romano, algunas escenas de ese ataque y poco más. Un ejemplo opuesto se encuentra en Spartaco, gladiatore della Tracia (R. Freda, 1953), que se abre con las desoladoras imágenes en blanco y negro de un poblado arrasado por las tropas romanas, en una alusión evidente a los daños sufridos por la población civil europea en el transcurso de la II Guerra Mundial. En este film la violencia brota siempre desde el ámbito romano, los esclavos se limitan a intentar defenderse de los abusos de Roma.

La referencia a las violaciones de mujeres romanas puede guardar alguna relación con el episodio de la matrona romana que fue igualmente violada y que acabó suicidándose; suceso que recoge Paulo Orosio y del que nos ocuparemos más adelante.

La segunda mención de Salustio ${ }^{18}$ se refiere a dos mujeres galas que suben a una montaña a realizar unos sacrificios y descubren a tropas romanas escondidas y dispuestas a atacar el campamento servil. El alejamiento de las mujeres parece deberse a que se encontraban en una situación de impureza, al encontrarse en ese momento con el periodo. Como sucede en otras oportunidades en el relato de la revuelta por parte de los autores clásicos, el lector se encuentra ante situaciones concretas que parecen obedecer más a la necesidad de una fluidez narrativa que no a una necesaria veracidad. Resulta verosímil pensar que a lo largo de la sublevación la sensación de peligro acechando sobre los rebeldes sería una constante, y que un medio para atenuarla sería la realización de ofrendas y sacrificios propiciatorios; el hecho de que las mujeres se encontraran en el particular estado de impureza explicaría la razón de por qué deben cumplimentar los ritos lejos del campamento, en plena naturaleza, lo que, de paso, explica cómo descubren a los romanos y logran conjurar un peligro real.

Pero, más allá de la anécdota, lo importante es que la presencia femenina viene asociada a la órbita religiosa, a los cultos y los sacrificios; una idea muy en línea con el pensamiento romano que tendía a vincular a las mujeres bárbaras con la religión. Su origen galo recuerda la división que

18. Hist. IV, 40. También se encuentra, con alguna variante, en Plutarco (Crass. XI, 4). 
se atisba, sobre todo al inicio de los acontecimientos, entre gladiadores galos, germanos y tracios que convivían en el ludus capuano ${ }^{19}$. Las mujeres a las que se refiere Salustio podían ser las compañeras de algunos de los gladiadores que inician la revuelta. También, el hecho de sean ellas la que realicen los sacrificios podría denotar algún tipo de jerarquía interna en la que las mujeres que estuvieron presentes desde el inicio dispondrían de algún tipo de privilegio, como es la potestad de la realización de los sacrificios, es decir, de controlar las relaciones con el ámbito de los dioses. El hecho de que esas mujeres se dirigieran hacia una montaña también nos podría indicar que poseían un determinado conocimiento del terreno, por lo que no resultaría exagerado pensar que podría tratarse de mujeres de la zona, lo que nos conduciría de nuevo al problema de cuáles fueron los apoyos reales de la insurrección, si una mayoría de esclavos o también un porcentaje considerable de población local libre, familias de campesinos y de pastores, sobre todo.

Este mismo episodio va a ser recogido con algún añadido por Plutarco; el autor griego aporta el dato de que ambas mujeres pertenecían a la partida rebelde liderada por Casto y Gánico; además de que, en lugar de hablar de un ejército romano escondido, los sorprendidos solo fueron un cuerpo de exploradores.

Plutarco aporta también la referencia más conocida sobre la presencia femenina en la revuelta. El pasaje en cuestión ${ }^{20}$ asocia a la compañera de Espartaco con la religiosidad. Cuenta el historiador griego que Espartaco soñó que una serpiente se enroscaba en su rostro; su compañera, tracia como él, y sacerdotisa de los cultos dionisíacos lo interpretó como el presagio de un gran poder que le estaba aguardando ${ }^{21}$.

Varios son los aspectos que pueden ser comentados a partir del episodio del sueño y su interpretación. El primero sirve para recordar que los sueños son, en el mundo antiguo, una de las vías de comunicación más directa e inmediata entre dioses y hombres. La encargada de adivinar el

19. Para Theodor Mommsen la división interna de los rebeldes fue debida a motivos étnicos; en su exposición diferenciaba a Espartaco del resto, tomando como base el testimonio de Plutarco que lo presentaba casi como un heleno. Posteriormente, el historiador S. I. Mishulin cambió la división étnica por la social, entre libres y esclavos, estos últimos dotados de un ideario revolucionario. Orena, Rivolta e rivoluzione, 44 y ss., 65 y ss. y 83 ss.

20. Crass. VIII, 4.

21. Un episodio de características similares, esta vez protagonizado por la madre de Augusto, en el que también aparece una serpiente y que anticipa el poderoso futuro que le aguarda a su hijo se encuentra en Suet. Aug. XCIV. D. C. XLV, 2. Presagios semejantes siguen apareciendo siglos más tarde, relacionados con Septimio Severo (S. H. A. SS. I, 10), Maximino el Joven (S. H. A. M. I, 10) y Alejandro Severo (S. H. A. AS. XIV, 1). 
sentido del sueño es la compañera de Espartaco, sacerdotisa de Dioniso; esta divinidad estaba asimilada tanto a Apolo como al dios tracio Sabazio. En el culto a Sabazio, la serpiente desempeña un papel importante, ya que uno de sus ritos iniciáticos se realizaba mediante la simbólica unión sexual con el dios, que era representado por una serpiente que se introducía bajo las ropas del aspirante; el recorrido del animal por el cuerpo del iniciado simbolizaba la unión con el $\operatorname{dios}^{22}$. En este caso, al estar la serpiente en la cara del tracio podemos pensar que directamente podía recordar a una corona, de ahí la referencia al destino importante que estaría aguardándole.

Hay que recordar que uno de los atributos de Dioniso es su capacidad de ser una figura liberadora, es decir, que puede lograr que sus seguidores dejen de ser los que son para convertirse en otra cosa; en el caso de los esclavos rebeldes, Dioniso - y con él Espartaco- podría significar el final de la condición servil (aunque siempre a nivel individual ya que nunca se plantea acabar con la esclavitud como institución) ${ }^{23}$. La vinculación de la revuelta con Dioniso también se manifiesta en el área geográfica más afectada por los hechos — la Apulia y los Turios-, era una zona donde, desde los tiempos de Aníbal, más se habían desarrollado los cultos dionisíacos, a pesar de los intentos de Roma por ponerles freno ${ }^{24}$.

Aunque Plutarco no indica cuándo y dónde tiene lugar el sueño, este podría haber sido en el ludus de Capua poco antes del inicio de la revuelta. La pareja podría convivir en la escuela de gladiadores, y podemos pensar también que, en cierto modo, esa convivencia permitida por el lanista o propietario del ludus podría corresponderse a algún tipo de privilegio del que gozaría Espartaco. Tal vez por el hecho de ser algo más que un simple gladiador, tal vez un luchador ya alejado de la arena - una vez cumplida su condena-, y ahora convertido en el encargado de adiestrar a los nuevos gladiadores ${ }^{25}$. En todo caso, el suceso trasmitido por Plutarco vuelve a subrayar la relación de las mujeres que participaron en la revuelta con los cultos y la esfera religiosa. Dada la precariedad de información disponible, las hipótesis no pueden ir más allá.

El último de los fragmentos a consignar nos conduce al siglo IV d. C, su autor es Paulo Orosio, que escribe desde una visión cristiana. Orosio

22. Masiello, "L'ideologia", 185.

23. Algunos años antes de la revuelta, en el 88 a. C., cuando el rey del Ponto, Mitrídates, invadió los territorios romanos situados en Asia, la población local lo aclamó como un nuevo Dioniso que traía la libertad. D. S. XXXVII, 26. Masiello, "L'ideologia", 188. 8-19.

24. El principal episodio represivo fue la persecución de las Bacanales. Liv. XXXIX,

25. Guarino 1980, 325-327. 
se refiere a una matrona romana que tras ser violada se suicidó. Durante su funeral los esclavos rebeldes organizaron combates de gladiadores en donde tomaron parte cuatrocientos prisioneros romanos ${ }^{26}$. Orosio coloca el episodio en un contexto de matanzas, incendios, robos y violaciones llevadas a cabo por los rebeldes; es decir, el aspecto más material, trágico y violento del episodio, el daño real e irreversible padecido por la población civil durante la revuelta.

Tres autores romanos anteriores a Orosio - Cicerón ${ }^{27}$, Floro ${ }^{28}$ y Apiano $^{29}$ - consignan unos acontecimientos muy similares. Ellos refieren que los esclavos celebraron unos combates de gladiadores en donde tomaron parte cuatrocientos prisioneros romanos, pero en honor de Crixo, otro de los líderes de la revuelta, que había muerto en el campo de batalla. En base a estos datos podemos pensar que Paulo Orosio adapta un suceso ya recogido con anterioridad a los intereses de su obra. Y siempre dándole forma a unos hechos perfectamente verosímiles en el transcurso de la revuelta $-\mathrm{y}$, en general, en cualquier conflicto-, como es la violación de mujeres.

A Cicerón, Floro y Apiano les interesa subrayar el riesgo real que la revuelta suponía para Roma; ya que la organización de esos combates por parte de los esclavos, en donde los prisioneros romanos (jurídicamente libres) luchan como gladiadores (carentes de derechos civiles y de protección jurídica), era una inversión en toda regla del orden romano. Mayor amenaza que la destrucción de todo lo que significaba Roma no podía haber. En el episodio de los combates de gladiadores, además, se detecta la humillación que la revuelta representaba para Roma, no solo obligada a enviar a sus legiones a luchar contra esclavos, sino que además debían ocupar en la arena el lugar de criminales y condenados. A los daños materiales se les unen los morales con lo que el eco de los hechos iniciados en Capua difícilmente se borrarán de la memoria colectiva romana ${ }^{30}$.

Pero para Orosio los objetivos a la hora de escribir son diferentes. Realiza una apología de sus creencias religiosas, una de las opciones para ello es mostrar cómo las desgracias padecidas por Roma fueron mucho mayores en momentos anteriores a la instauración del cristianismo como religión imperial. De ahí la reutilización que realiza del episodio citado, salvo

26. Hist. V, 24, 3 .

27. De Hauris. XII, 26.

28. II, 8, 9.

29. B. C. I, 117.

30. Hay que destacar que, como ya sucedió en la primera revuelta de Sicilia, los sublevados no disponen de un modelo alternativo social, político, jurídico o lúdico, sino que imitan y hacen suyo el que mejor conocen, en este caso, el romano. 
que aceptemos la hipótesis de que, durante el transcurso de la revuelta, los esclavos organizaran, al menos, dos munera en donde tomaron parte idéntico número de combatientes. Orosio le da forma a un acontecimiento verosímil utilizando para ello hechos reales, ficticios y referencias mitológicas.

En la obra del autor cristiano el suceso es narrado con mayores dosis de dramatismo, centrándose en la figura de la matrona romana que, no soportando la humillación por la violación sufrida, opta por suicidarse en un ejercicio de virtud y pudor cristiano llevado al siglo I a. C. ${ }^{31}$. En el imaginario romano, esta historia, se conectaba de inmediato con el suicidio de Lucrecia, que en las páginas de Orosio aparecería actualizado y, en buena medida, cristianizado. El homenaje que el comportamiento de la matrona recibe por parte de los esclavos subraya la validez de los valores cristianos.

Los combates de gladiadores tuvieron un origen religioso, asociado a los funerales de grandes personajes en cuyas exequias fúnebres se sacrificaba, en un principio, a prisioneros, que, en un segundo momento, lucharían ante la pira funeraria para verter la sangre que servía de alimento al difunto ${ }^{32}$. En Roma, la vinculación de los combates de gladiadores con la esfera funeraria tardó mucho en desaparecer; las primeras luchas atestiguadas en la ciudad datan del año 264 a. C. y fueron organizadas por los hijos de Bruto Pera para conmemorar la muerte de su padre ${ }^{33}$. Y, de hecho, aunque en la tardorrepública se convirtieron en un instrumento de la lucha política, al menos nominalmente no perdieron su conexión funeraria, y así Julio César organizó unos juegos, que incluían combates de gladiadores, para honrar la muerte de su hija ${ }^{34}$. Por lo tanto, la celebración organizada por los esclavos rebeldes, ya fuera en honor de Crixo o de la anónima matrona, se encuadra dentro de la tradición romana.

El elevado número de prisioneros que participan en los combates ofrece una pista más de las dimensiones alcanzadas por la revuelta. Y nos recuerda que, más adelante, los sublevados volverán a sacrificar prisioneros romanos; será durante el asedio al que son sometidos por las tropas de Craso en el Bruttium, donde, para rellenar la zanja que les rodea, estos

31. Capozza, "La tradizione», 11 y s.

32. En los funerales de Patroclo, los sacrificados son jóvenes pertenecientes a la aristocracia troyana. Hom. Il. XXIII, 22-23 y 174-176.

33. Val Max. II, 4, 7.

34. Suet. Caes. XXVI, 3. D. C. XLIII, 22, 3; 23, 2. La desaparición del elemento funerario no supuso que los elementos religiosos desaparecieran del mundo de los $l u d i$, siendo, de hecho, una presencia constante independientemente del escenario donde tuvieran lugar, ya fueran teatros, circos o anfiteatros. 
deciden cubrirla con los cadáveres del ganado y los prisioneros para así poder desplazarse sobre ellos ${ }^{35}$.

Como hemos podido comprobar, la escasez de testimonios sobre la revuelta de Espartaco que recojan la presencia femenina hace muy difícil determinar qué papel desempeñaron en el transcurso de los acontecimientos. La parca información de la que disponemos nos permite, tan solo, recordar que son objetos de la violencia desencadenada, además de que, entre las filas sublevadas, parecen tener una vinculación con los cultos religiosos.

Podemos cifrar la presencia de Espartaco en las pantallas de cine y televisión en alrededor de cuarenta ocasiones; hay que destacar la variedad de géneros en la que ha aparecido, así como la alternancia entre papel protagonista de la acción, secundario o como simple reclamo o figura anecdótica.

Hasta la llegada del cine sonoro podemos consignar casi con total seguridad cuatro producciones sobre Espartaco, tres producciones italianas y una realizada en la Unión Soviética. La primera de ellas fue Spartaco, un proyecto entre la Latium Film y la Societá Pineschi dirigida por Oreste Gherardini en el año 1909. En veintiséis cuadros, trasladaba a la pantalla la novela de Raffaele Giovagnoli ${ }^{36}$. Aunque la gran producción sobre Espartaco se rodó cuatro años después, en 1913, producida por la casa turinesa Pasquali Film bajo la dirección de Giovanni Enrico Vidali. Spartaco (Il Gladiatore della Tracia) constituye un neto exponente de lo que es el Kolossal italiano que alcanzó el reconocimiento de críticos y público de Europa y Estados Unidos en los años previos a la I Guerra Mundial. Protagonizada por Mario Guaita, más conocido como «Ausonia» «", la película reducía la revuelta a la fuga de los gladiadores y su posterior victoria sobre Craso; la acción apenas supera los límites de la ciudad de Roma, Espartaco aparece perfectamente integrado en la vida urbana, alterna con el poder y tras celebrar una ceremonia del triunfo ordena la liberación de los esclavos. Siguiendo los tópicos del género al que pertenece, no pueden faltar la escena de las ejecuciones con felinos y las intrigas y romances ${ }^{38}$.

Mucha menos información, e incluso seguridad de su existencia, se dispone de otros títulos del periodo mudo; cabría destacar un nuevo

35. Front. Strat. I, 5, 20.

36. Bernardini, Il cinema, 404 y s. Chiti, Dizionario, 139. Wyke, Projecting, 41-47.

37. Un actor que mezclaba la tradición del forzudo propio del Kolossal, heredero de personajes como Ursus y Maciste, con el cine más acrobático y funambulista.

38. Martinelli, «Espartaco», 64-65. Bernardini y Martinelli, Il Cinema, 261 y ss. Chiti, Dizionario, 293. 
Spartaco producido por la casa Pineschi en el año 1919 (intentando, suponemos, recuperar el prestigio y la audiencia del Kolossal, pero en un contexto nacional e internacional totalmente diverso y desfavorable), y también la producción soviética Spartak de $1927^{39}$.

Espartaco retorna a las pantallas cinematográficas más de dos décadas después, cuando, a comienzo de los años cincuenta, se estrene Spartaco, il gladiatore della Tracia, bajo la dirección de Riccardo Freda en $1953^{40}$. El cine sobre el Mundo Antiguo había recuperado el vigor en taquilla de antaño, tras el paréntesis de la II Guerra Mundial, con títulos emblemáticos como Sansom and Delilah (C. B. DeMille, 1949), Fabiola (A. Blasetti, 1949) o Quo Vadis? (M. LeRoy, 1951). El film de Freda se inserta dentro de una serie de títulos sobre la Antigüedad que en la década de los cincuenta se realizaron en Italia antes de la eclosión del péplum. En muchos de ellos, la mujer tenía un papel protagonista ${ }^{41}$, algo que desparecerá con el monopolio de los forzudos, impuesto por el péplum.

En la película de Freda, el papel de Espartaco estuvo interpretado por Massimo Girotti; fue rodada con una fotografía en blanco y negro que potenciaba el tono fuertemente amargo de la trama, en donde se mezcla el romance con la reflexión acerca de la responsabilidad de los líderes para con - en este caso- la revuelta y sus seguidores. El espectador puede encontrar, además, una particular naumachia rodada en el anfiteatro de Verona, en donde se conjugan dos tópicos del género como es una escena de danza con la presencia de los leones.

Pocas películas han ayudado a identificar tanto a un personaje de la Antigüedad con un determinado actor y a unos hechos del pasado con lo mostrado en pantalla como el Spartacus (1960) de Stanley Kubrick. La conjunción de intereses y rivalidades delante y detrás de la cámara entre el director, el productor y protagonista, el elenco de actores, el guionista y el novelista acabaría por crear un film que desarrolla un discurso contemporáneo sobre la libertad individual y la opresión política, sobre el peligro del poder autoritario y la necesidad de la solidaridad y el activismo para ponerle freno. Spartacus convertía en imágenes la situación política y social de los Estados Unidos en los convulsos años de la Guerra Fría, hablando por igual de la antigua Roma que del Hollywood contemporáneo.

39. Lebedev, Il Cinema muto, 526.

40. Dumont, L'Antiquité, 293 y s. Della Casa y Giusti, Il grande libro, 290. Lapeña, "The stolen", 171-182.

41. Con títulos como Messalina (C. Gallone, 1951), La regina di Saba (P. Francisci, 1952), Attila (P. Francisci, 1954) o Teodora, imperatrice di Bisanzio (R. Freda, 1954). 
El éxito y la influencia ejercida por el film de Kubrick propiciaron que el personaje de Espartaco se hiciera un hueco en la producción de pepla, en donde hasta ese momento no había tenido ninguna presencia. Podemos consignar cuatro títulos en donde aparecen Espartaco y su mito ${ }^{42}$. El primero de ellos fue Il figlio di Spartacus del realizador Sergio Corbucci en 1962; aquí, un centurión romano descubre ser el hijo del gladiador tracio comenzando, de esa manera, su lucha contra los romanos corruptos (que no contra Roma), personificados en la figura de Craso. Un hilo argumental con puntos en contacto se encuentra en La vendetta di Spartacus (M. Lupo, 1964), en donde un grupo de rebeldes hace correr el rumor de que Espartaco sigue vivo. De ese mismo año, 1964, es la película Gli invincibili dieci gladiatori (también comercializada como Spartacus e i dieci gladiatori), dirigida por Nick Nostro y en donde, en esta ocasión, aparece el gladiador tracio uniendo sus fuerzas con los diez gladiadores del título. Finalmente, en 1965, el realizador Domenico Paolella firmó Il gladiatore che sfidó l'impero, una película que presenta la peculiaridad de convertir a Espartaco en un culturista propio del péplum, y hacerlo viajar en el tiempo para enfrentarlo a Nerón, el emperador más cinematográfico de todos.

En 1955 el músico armenio Aram Kachaturian compuso el ballet Spartakus; se estrenó al año siguiente en Leningrado aunque no será hasta 1958 cuando se le componga una nueva coreografía. Dividido en tres actos y en diez escenas, el ballet se gestó como un homenaje al precursor de la lucha de clases, es decir, que seguía los postulados de la historiografía marxista del siglo XX sobre Espartaco, al que convertían en el líder de la revuelta considerada como un primer episodio del conflicto entre la burguesía y el proletariado. Desde los años setenta del pasado siglo tenemos adaptaciones televisivas del ballet, como fueron Spartakus (V. Derbenyov e Y. Grigorovich, 1975), Spartak (Y. Grigorovich y P. Motell, 1984), Spartacus (The Australian ballet) (L. Sergei y L. Dreson) o Spartak (N. Kasatkina y V. Vasiliev, 2003).

La proliferación a lo largo del siglo XXI de canales de televisión especializados en temas relacionados, de un modo u otro, con la historia, el patrimonio o la arqueología ha tenido como consecuencia la producción, de unos años a esta parte, de una ingente cantidad de documentales. Esto se hace para cubrir esa demanda cada vez más creciente, y se ve enormemente favorecido por el recurso a las reconstrucciones digitales e informatizadas de ciudades y edificios del pasado. Se trata de documentales muy alejados de aquellas primeras producciones del siglo XX en donde las imágenes rodadas en museos o yacimientos arqueológicos se

42. Della Casa y Giusti, Il grande libro, 155 y s., 167 y s., 187 y s., y 325 s. 
alternaban con intervenciones estáticas de representantes del mundo académico. Hoy día, las bibliotecas, los siempre abigarrados despachos universitarios o las salas de los museos han dejado espacio a las coloridas y animadas recreaciones informáticas de la Antigüedad. En este contexto de producción encontramos diferentes documentales centrados en la revuelta de Espartaco, entre las que podemos mencionar The real Spartacus (B. Lyons, 2001); Spartacus, uno de los diecisiete episodios de la serie Decisive battles (2004); Spartacus: gladiator war (D. Oliver, 2005), o Spartacus (T. Dunn, 2008).

El número no muy amplio de producciones sobre Espartaco contrasta con la gran diversidad de géneros o formatos narrativos en donde aparece. Además de los ya mencionados hasta el momento, el personaje aparece también en series de animación para el mercado televisivo, caso de la italiana Spartacus (O. Corradi, 2006) ${ }^{43}$, o en cintas dirigidas para el cine para adultos, en este caso relacionada con la pornografía de temática gay, con títulos como House of Spartacus I y II (K. Jones, 1993) o Gladiator School Orgy (2004) $)^{44}$. Aunque también lo encontramos a él y a la revuelta apareciendo en géneros en principio muy alejados de los presupuestos narrativos y argumentales del cine histórico, como pueden ser el musical - caso de la producción francesa Spartacus le gladiateur, il revait d'etre libre (E. Chouraqui, 2005)—; la comedia —SPQR 2000 y 1/2 anni fa (C. Vanzina, 1994)— ${ }^{45}$, o en el cine de terror con la película italiana Morituris, dirigida por Raffaele Picchio en el año 2008. En este último título el espectador asiste a la venganza de Espartaco y los suyos siglos más tarde mediante el asesinato y la posterior crucifixión a lo largo de la Vía Apia de aquellos que se aproximan a Capua, en una evidente alusión a los seis mil supervivientes crucificados ${ }^{46}$.

Dejamos para el final las producciones realizadas para el formato televisivo. Del año 2004 es la miniserie Spartacus, dirigida por Robert

43. Dumont, L'Antiquité, 301.

44. La vinculación de Espartaco con la comunidad gay adquiere visualización y amplia repercusión desde 1970 con el nacimiento de la Spartacus International Gay Guide, una guía de viajes dirigida al colectivo gay de ámbito internacional y que, a día de hoy, continúa editándose. El nacimiento de la vinculación creemos que tiene un origen cinematográfico, que se remite a una escena de la película Spartacus de Stanley Kubrick (1960), en donde Craso intenta seducir sin éxito al esclavo Antonino. La situación obedece, obviamente, a comportamientos morales y sexuales de la segunda mitad del siglo XX, sin conexión alguna con la idea de sexualidad romana del siglo I a. C.

45. La referencia a la revuelta aquí es muy reducida y limitada al final de trama con la aparición de los rebeldes crucificados en la vía Apia.

46. App. B. C. I, 120. Utilizando un recurso propio del cine de terror, los gladiadores asumen la forma de muertos vivientes. 
Dornhelm. La película combina influencias del Spartacus de Kubrick con referencias a la novela de Howard Fast que estaba en la génesis del film de los sesenta. Todo ello unido a los inevitables peajes que hay que cumplimentar para adaptar el producto a las demandas y a la sensibilidad del público del siglo XXI; el mejor ejemplo lo tenemos en la escena que recrea el sacrificio del caballo por parte de Espartaco, quien, obviamente, no lo mata sino que lo deja marchar en un gesto de clemencia acorde con el pensamiento proteccionista hacia los animales cada vez más extendido por la sociedad. El episodio — recogido por Plutarco- ${ }^{47}$ constituye en sî mismo una ceremonia para fortalecer la unión con sus tropas mandando el mensaje de que si vencen tendrán los caballos que quieran y si, por el contrario, son derrotados, de nada les servirían las cabalgaduras. De paso sirve para seguir dándole a la figura de Espartaco un cariz religioso que no aparece en otros testimonios salvo en Plutarco ${ }^{48}$.

Hasta la fecha, la última gran producción — sobre todo por el impacto sobre la audiencia de las dos primeras temporadas emitidas- sobre Espartaco ha sido Spartacus (2010-2013), de la productora norteamericana Starz. El resultado final, tres temporadas y una breve precuela, estuvo muy condicionado por la enfermedad del actor que iba a interpretar al protagonista — el galés Andy Whitfield—, que falleció al término de la primera temporada. La serie se inicia con Spartacus: blood and sand (2010), que narraba desde la llegada al ludus de Capua de Espartaco hasta el estallido de la revuelta, es decir, todo el periodo de formación como gladiador, además de ir presentando a todos los personajes y fragmentarse la trama principal en multitud de ramificaciones marcadas por las intrigas políticas y los asuntos domésticos, vinculados al romance y al sexo. Debido a la fatal enfermedad ya comentada, en 2011 se emitió la precuela Spartacus: Gods of the Arena, en donde en seis episodios se narraba la historia de la familia de Lentulo Batiato y la creación de la escuela de gladiadores. Spartacus: vengeance (2012) se ocupaba de los primeros pasos de la revuelta, cuando los esclavos huidos permanecen acampados en el Vesubio. Mientras que Spartacus: war of the dammed (2013) desarrollaba el tema de la revuelta hasta su derrota definitiva. Estéticamente la serie está muy influenciada por lo que podemos denominar la estética $300^{49}$, tanto a la hora de mostrar los cuerpos como los combates. Mientras que, en la

47. Crass. XI, 9 .

48. En diversas culturas de Europa y del Próximo Oriente, el caballo aparece relacionado con el sol y la fecundidad, siendo su sacrificio un símbolo del acto supremo de la creación. Capozza, "Spartaco e il sacrificio», 252 y ss.

49. En referencia al modo en que la violencia es mostrada en la película 300 ( $\mathrm{Z}$. Snyder, 2006). 
manera de abordar asuntos morales o sexuales, hay una clara presencia de títulos como el Caligola producido por la revista Penthouse y dirigido, aunque no reconocido, por Tinto Brass en 1979.

El tercer apartado del presente trabajo quiere ser un análisis más detenido sobre la presencia femenina en las recreaciones cinematográficas y televisivas de la revuelta de Espartaco, en busca del papel que desempeñan en ella tanto las mujeres romanas como las del bando rebelde. No pretendemos una simple comparación con los testimonios romanos, no solo por el carácter limitado y fragmentario de los mismos, sino porque estamos convencidos de que los medios audiovisuales reescriben el pasado utilizando otros mecanismos, otros lenguajes y están movidos por otros intereses opuestos a la historiografía escrita que hacen imposible una comparación. Un acto, el de comparar textos y pantallas, que no conduciría a nada salvo a instantes de vanidosa y vacía elocuencia. Baste recordar que para los autores romanos el propio sentido de lo que entendemos por historia difiere bastante de nuestra actual estructura académica.

Una de las características definitorias del cine sobre la Antigüedad, y en especial del péplum, es el planteamiento maniqueo con el que se muestran las tramas y los personajes. Y es en el maniqueísmo donde se encuentra la base a la hora de definir en las pantallas a los personajes femeninos que aparecen en las producciones sobre Espartaco y la revuelta. Se trata, en definitiva, de modelos y ejemplos de comportamientos en constante oposición y destinados a ser imitados o a ser rotundamente rechazados por la audiencia. Los primeros modelos se asocian, generalmente, a mujeres cristianas, de bajo estatus socioeconómico y muy habitualmente esclavas. Mientras que los segundos aparecen monopolizados por mujeres pertenecientes a la elite romana.

En el corpus fílmico que aborda la figura y el mito de Espartaco y el episodio de la revuelta servil encontramos con toda nitidez la oposición excluyente entre los personajes de las aristócratas romanas y las mujeres esclavas que toman parte en los acontecimientos. Y, de hecho, en las películas de las que nos ocuparemos, y salvo excepciones, se muestra casi mayor interés y están mejor desarrollados —es decir, como figuras complejas y ricas en matices- los personajes de las mujeres romanas que los de las esclavas, que suelen aparecer mucho más planos y, en muchos casos, como una sucesión de estereotipos. La complejidad de la que hablamos ha de entenderse siempre dentro de la esquematización de roles propia del péplum.

En el conflicto básico entre ambos modelos, más que versar sobre la oposición o el binomio libertad/esclavitud, lo que la audiencia ve en la pantalla es una lucha por conquistar y seducir a Espartaco, por lo que, en 
cierto modo, el gladiador tracio se convierte en el objetivo o el botín en ese juego de estrategias que se establece entre ambos modelos femeninos.

Aunque, lógicamente, siempre se pueden encontrar excepciones. Así, en Spartaco. Il gladiatore della Tracia (G. E. Vidali, 1913) $)^{50}$, la trama muestra una insólita complicidad entre ama y esclava; Narona, la primera de ellas, es la hija de Craso y está enamorada de Espartaco; y la segunda, Idamis, es la hermana del tracio. Esta extraña alianza femenina se debe en buena medida a que la película estaba inspirada en la novela Spartaco (1874), del periodista Raffaello Giovagnoli; el autor, convencido seguidor de Garibaldi, convierte en las páginas de su novela al tracio no solo en un enemigo de Roma, sino también en alguien interesado, por momentos, en librarla de la corrupción política. Este planteamiento se traslada a la pantalla, dándole sentido final a la cooperación entre ambas mujeres para salvar a Espartaco de los peligros y las trampas que le acechan y, por ende, a la propia Roma. Ello no es óbice para que, en el primer encuentro con Espartaco, la aristócrata romana aparezca rodeada de aquellos elementos que subrayan el lujo, el capricho y la indolencia, como la abundancia de cojines, sedas, plumas y la posesión de felinos como mascotas. A pesar de la referida complicidad entre ambas mujeres, en todo momento se detecta la superioridad de Narona; la suya es una postura protectora que propicia el permanente agradecimiento y sumisión por parte de Idamis. Ellas son las únicas mujeres que en la película escapan del anonimato; al margen de ellas dos, en la pantalla se puede detectar más presencia femenina entre el público que celebra el triunfo de Craso por las calles de Roma, en el graderío desde donde la multitud contempla los combates de gladiadores o, ya casi al final de la acción, en el grupo de plañideras que acompaña el cadáver del hermano de Craso.

La película Spartacus (S. Kubrick, 1960), al margen de haber modelado una imagen física del personaje difícilmente superable, utilizó el episodio histórico de la fallida revuelta servil para construir un discurso contemporáneo acerca del peligro real de la implantación de una política totalitaria que se cernía sobre los Estados Unidos a mediados del siglo XX. Hay que recordar que, en la película, la derrota final de los esclavos es solo aparente, ya que concluye con un mensaje esperanzador (el hijo de Espartaco, ya libre, abandona Roma), que emplaza a los espectadores a comprobar cómo el negado triunfo servil se alcanza en época contemporánea, en un presente sin el estigma de la esclavitud ${ }^{51}$.

50. Martinelli, «Espartaco», 64 y s.

51. Entre la abundante bibliografía sobre la película de Kubrick, y a modo de introducción, podemos citar: Bonet Mójica, Espartaco. Lapeña, El mito. Winkler, Spartacus. 
Con respecto a la presencia femenina en la película, hay que destacar la escasa importancia que presenta con respecto al desarrollo de la revuelta y de la propia trama del film. Eso sí, en la pantalla aparecen numerosas esclavas anónimas tanto en las casas de aristócratas romanos como en el ludus que regenta Batiato; estas últimas, junto a las que se unirán posteriormente a la revuelta, están empeñadas en asuntos domésticos y de avituallamiento — cocineras, niñeras, aguadoras...- ${ }^{52}$, unas tareas que, paradójicamente, seguirán realizando en el campamento rebelde.

La presencia de mujeres romanas se limita a Helena y Claudia, las dos patricias que acompañan a Craso en su visita a la escuela de gladiadores $^{53}$, en donde verá por primera vez a Espartaco. Un reducido papel pero que condensa muchos de los atributos que suelen acompañar a la mujer romana en las pantallas. Son crueles, frívolas, libidinosas y caprichosas; ellas fuerzan la celebración del combate, seleccionan a los gladiadores e indican cómo irán pertrechados. La lucha se convierte en una exhibición de cuerpos musculosos para disfrute de las aristócratas romanas. El disfrute, con matices que van desde la refinada crueldad hasta el erotismo, de la visión de los combates de gladiadores es otro atributo que acompaña en el cine a la mujer romana. Por regla general ellas solo se entregan al goce de todo tipo de placeres sin interesarse casi nunca por otros asuntos $^{54}$.

El único personaje femenino mostrado con más profundidad es el de Varinia, la compañera del tracio; ella evoluciona de ser un simple objeto sexual a repartir entre los gladiadores ${ }^{55}$ hasta convertirse en la heredera y administradora del legado de Espartaco, manifestado en el hijo que va con ella en su salida de Roma una vez lograda la libertad. Lo peculiar del film de Kubrick es que Varinia no debe competir con otra mujer por conquistar a Espartaco, sino que su rival será el hombre más poderoso de Roma, Craso, obsesionado en poseerla a ella, a Espartaco y a la misma

Douglas, Yo soy. Matellano, Espartaco. Edición especial 50. Matellano, Espartaco. El libro del 60 .

52. Las esclavas también serán utilizadas como objetos sexuales, siendo repartidas entre los esclavos. Propiciando de ese modo el encuentro entre Espartaco y Varinia.

53. Aunque hemos de pensar que también serían romanas libres, en su mayoría, las mujeres que se aprecian en la multitud que recibe la entrada de las tropas serviles en una ciudad anónima; una escena que, por cierto, recuerda a los noticiarios de la II Guerra Mundial que mostraban la entrada del ejército norteamericano en diferentes ciudades europeas.

54. De la Rosa, "Esclavas y patricias», 41.

55. De la Rosa, "Esclavas y patricias», 43. En comparación con el personaje en la novela de Howard Fast, la Varinia del film de Kubrick resulta más civilizada y con menos carácter guerrero. Martín Rodríguez, «De la historia», 214 y ss. 
Roma. La bisexualidad de Craso subraya su desmedida ansia de poder, el apetito sexual dirigido hacia mujeres y esclavos es una manifestación del afán por hacerse con el control absoluto de Roma.

Varinia no parece disfrutar de ningún privilegio especial por el hecho de ser la compañera de Espartaco. Trabajaba desempeñando tareas domésticas en el ludus y las seguirá haciendo en el campamento rebelde, con el añadido de que se la ve, también, cuidando y bañando a niños pequeños. Hay una escena en particular donde, estando ya embarazada, sirve sonriente el vino en el transcurso de una cena donde están reunidos Espartaco junto a otros gladiadores; ellos parecen algo achispados por el vino y ella parece feliz ejerciendo el cuidado del hogar y de su compañero. Un rol tradicional que se complementa con el que desempeña cuando está a solas con Espartaco; en esos momentos, dejando a un lado los dedicados al romance, ella asume el papel de consejera, solo ella conoce los miedos y los pensamientos reales de Espartaco. Es ahí cuando Varinia parece ejercer una superioridad intelectual sobre el tracio que, recordemos, es un analfabeto a lo largo de toda la película. Varinia aparece, además, como un personaje vital para el desarrollo de la trama, ya que - aunque la revuelta realmente se inicia con la negativa de Draba a acabar con la vida de Espartaco y su posterior ataque a Craso- ${ }^{56}$ el detonante de la rebelión llegará cuando el tracio ve partir a Varinia del ludus, una vez que la esclava ha sido vendida por Batiato. La constatación del hecho de que no van a volverse a ver se convierte así en la peor consecuencia posible de la, hasta ese momento, soportable esclavitud. Un recurso cinematográfico que potencia el elemento dramático dejando el aspecto político en segundo lugar, una vertiente que se manifiesta a través de las decisiones de Draba y en la posterior imagen de su cadáver colgado en el ludus sirviendo de escarmiento para el resto de los esclavos.

En la parte final del metraje, Varinia sortea el acoso al que la somete Craso, elude la tentación de la libertad, los lujos y la riqueza que le ofrece el aristócrata y acaba por aparecer como emblema de la fidelidad. Al no poder poseerla, Craso tampoco lo puede hacer con su compañero, certificando así su derrota. Una derrota confirmada cuando Varinia, ya convertida en madre y libre, abandona Roma tras despedirse del moribundo Espartaco $^{57}$.

56. Prieto, «Miedo", 377.

57. La decisión de Kubrick de que Espartaco muriera crucificado era otro de los cambios introducidos para rebajar el tono abiertamente izquierdista del guion de Dalton Trumbo. Prieto, «Miedo», 366. 
La particular competición entre mujeres romanas libres y esclavas por hacerse con Espartaco se mantiene incluso en aquellos títulos en donde la presencia femenina es mucho más reducida. De hecho, resulta extraño que en la trama aparezca junto al héroe solo uno de los modelos propuestos. Una excepción la constituye Il Gladiatore che sfidó l'impero (D. Paolella, 1965), en donde, además de tener que enfrentarse a un gladiador forzudo que asume la identidad de Nerón, Espartaco ha de hacer frente al doble juego de la romana Livia, quien, al tiempo que sirve los intereses de su padre - rival del tracio-, acaba por enamorarse de este, siendo redimida gracias a sus buenos sentimientos.

En el péplum es muy habitual que el amor sea el arma que finalmente derrote a las mujeres malvadas, en cuanto que gracias a él se «restaura» el orden alterado por la presencia de estas mujeres, que en su relación con los héroes suelen adoptar posturas habitualmente atribuidas a los hombres, es decir, manteniendo actitudes activas en la relación. Al final del relato estas mujeres o bien desechan ese modo de comportamiento para adoptar posturas más sumisas o pasivas (objetos que proteger y rescatar, amén de potenciales creadoras de una familia), o bien reciben un castigo ejemplarizante en forma de muerte, abandono y soledad.

Este planteamiento narrativo se observa en Spartaco, il gladiatore della Tracia (R. Freda, 1953) ${ }^{58}$; la película vio como algunas de sus escenas fueron censuradas debido al comportamiento del personaje de la patricia Sabina en su romance con Espartaco. Aunque se prohibieron algunas imágenes que mostraban un exceso de desnudez — para los dictados de la época-, lo que fundamentalmente se omitió fue la actitud activa de la mujer, que toma la iniciativa a la hora de besar al tracio, que mantiene con ella una postura pasiva ${ }^{59}$. Un intercambio de roles que la pantalla no podía ofrecer como alternativa válida al discurso oficial en donde el hombre debía tomar siempre la iniciativa ante la pasividad femenina. El film de Freda se presenta como una tragedia en donde Espartaco vive obsesionado con la idea de estar traicionando a la rebelión y a sus compañeros de armas. Un torturador sentimiento de culpa que viene propiciado por la relación que mantiene con la hija de su enemigo Craso. Sabina acumula buena parte de los tópicos con los que el cine ha caracterizado a la mujer romana de la aristocracia. Es cruel, refinada, en ocasiones indolente, de marcada sensualidad; una mujer que disfruta por igual estando junto a Espartaco que viendo los violentos espectáculos de la arena, y

58. Lapeña, «The stolen", 171 y ss.

59. Baldi, Schermi, 38. 
que mantiene al tracio en sus aposentos como si se tratara de un trofeo conquistado.

El personaje femenino antagonista de Sabina presenta la originalidad de su gran fortaleza, especialmente si se la compara con la habitual fragilidad o dependencia hacía el héroe mostrada por otros modelos pertenecientes a las mujeres esclavas. Ya desde la primera escena, Amitis se enfrenta a los soldados romanos que entran en su ciudad destruida: es tracia, como Espartaco, y tras un malentendido inicial acabará enamorada del gladiador. Presenta la salvedad de que, cuando el tracio abandona el campamento servil para estar con Sabina, ella prácticamente asume el liderazgo de la revuelta. Y será ella quien, tras la batalla final, encuentra a un moribundo Espartaco que le entrega su espada en un claro mensaje esperanzador de que la lucha aún no ha concluido. No deja de resultar paradójico que aquí el símbolo de la confianza en el triunfo futuro de los esclavos y los desfavorecidos sea una espada y en el film de Kubrick ese papel lo asuma el hijo de Varinia y Espartaco. Precisamente la productora del film norteamericano compró los derechos de distribución de la cinta italiana para retirarla de los circuitos comerciales para evitar de ese modo comparaciones entre dos maneras de reescribir un episodio del pasado ${ }^{60}$.

Hay veces que el espectador solo encuentra en la pantalla a uno de los modelos femeninos; ya vimos que sucedía en Il gladiatore che sfidó l'impero y también en La vendetta di Spartacus (M. Lupo, 1964), una película que gira alrededor del mito de Espartaco, ya que se inicia con el robo del cadáver del tracio por parte de algunos de sus seguidores que harán circular la noticia de que está aún vivo y al frente de una nueva revuelta. Prácticamente la única presencia femenina del film es Cintia, una esclava hermana de uno de los líderes rebeldes y, a su vez, enamorada de su antiguo amo que ha acabado por engrosar las filas serviles. Esa doble condición propicia que disfrute de una situación de privilegio con respecto a las escasas mujeres que aparecen en el campo rebelde. Ella, como Varinia o Amitis, acaba abandonando Italia subrayando así la idea de que solo alejándose físicamente de Roma es posible evitar la esclavitud y la tiranía.

En otras oportunidades Espartaco es solo un secundario en la trama de la película, como sucede en Gli invincibili dieci gladiatori (N. Nostro, 1964), una cinta que mezcla aventura, violencia y comedia ${ }^{61}$. El aspecto más destacado del film, por lo que se refiere a la presencia femenina, es la presentación positiva de los modelos presentados, tanto la noble romana

60. González, «Le cinéma américain», 310.

61. Y que prefigura la violencia burlesca e infantil que se extenderá a partir del modelo ya plenamente establecido en el film Lo chiamavano Trinità... (E. Barboni, 1970). 
como la esclava. La primera de ellas presta su ayuda desinteresada a los gladiadores protagonistas, mientras que la segunda asume el papel de esforzada y solidaria heroína incapaz de abandonar a su suerte a sus compañeros de cautiverio.

Por lo que se refiere a la miniserie de televisión Spartacus (R. Dolhem, $2004)^{62}$, lo más llamativo de la misma es que intenta conciliar tres influencias diferentes, ya que combina $-\mathrm{O}$ al menos pretende hacerlo- el film de Kubrick de 1960; la novela de Howard Fast, de la que es mucho más deudora, y las exigencias propias de la audiencia de comienzos del siglo XXI. De ahí que el personaje de Varinia ofrezca características diferentes a las de anteriores versiones. Siguiendo la obra de Fast, la compañera de Espartaco, en esta oportunidad de origen galo, aparece más independiente, con más carácter, en ocasiones más utópica en sus aspiraciones y, adecuándose al contexto sociocultural del nuevo milenio, con un pensamiento que podría ser catalogado como protofeminista ${ }^{63}$.

El presente recorrido por el corpus fílmico en donde la figura de Espartaco alcanza mayor relevancia concluye con la serie de televisión Spartacus (2010-2013); el proyecto, como mencionamos con anterioridad, estuvo muy condicionado por la enfermedad y posterior fallecimiento del actor Andy Whitfield ${ }^{64}$, obligando al rodaje de una temporada más breve que las otras en la que no aparecía el gladiador tracio. Las siguientes reflexiones, por lo tanto, se ocupan de las temporadas de 2010 (Spartacus: blood and sand), 2012 (Spartacus: vengeance) y 2013 (Spartacus: war of the Damned).

Obviamente, el formato televisivo permite unos metrajes mucho más amplios, por lo que en la serie encontramos un número de personajes femeninos mucho más elevado y también una mayor cantidad de tramas narrativas que se entrecruzan. Pero a pesar de ese crecimiento cuantitativo podemos decir que, básicamente, los personajes femeninos que aparecen son variantes o versiones de los dos modelos básicos que veíamos en producciones anteriores.

En cuanto a las tramas, se puede apreciar una que desarrolla la oposición y posterior enfrentamiento entre los romanos y los esclavos; una segunda se ocupa del mundo de los gladiadores: la instrucción, los combates, la vida cotidiana en el ludus y, especialmente, los conflictos entre ellos. Mientras que una tercera focaliza su interés en las intrigas folletinescas, sentimentales y sexuales que atañen a romanos y esclavos.

62. Lapeña, «Espartaco, el rebelde», 163-170.

63. Martín Rodríguez, "De la historia", 236 y s.

64. Melo, "Una plegaria», 1-16. 
A lo largo de las tres temporadas en donde aparece Espartaco se pueden distinguir más de una docena de personajes femeninos en mayor o menor medida relacionados con él ${ }^{65}$. Todos ellos tienen en común el hecho de que adoptan papeles mucho más activos que los consignados en producciones precedentes. Lógicamente, el modelo de la mujer sumisa que debe ser protegida, rescatada y salvada tiene escaso recorrido entre la audiencia de comienzos del siglo XXI. La heroína caracterizada por la pasividad y la falta de iniciativa es dejada a un lado en beneficio de otros modelos opuestos que manifiestan mucho más control sobre sus sentimientos, su cuerpo y su sexualidad. Y es que, como sucedía ya en la serie Rome (2005-2007), también aquí se muestra la conversión de los esclavos en simples objetos —independientemente de su sexo-, que son utilizados o ante los que se desarrolla la vida política, sentimental o sexual sin tenerlos en absoluto en consideración, meros elementos decorativos a los que usar una vez llegado el momento oportuno.

Mención especial merece el personaje de Sura, la compañera de Espartaco, que cobra protagonismo al inicio de la serie y que - aunque no aparezca físicamente en pantalla - se convertirá en la motivación que haga avanzar y actuar al tracio. Sura se acerca al modelo de mujer poderosa y guerrera que aparecía en la novela de Howard Fast sin perder los atributos proféticos que le concedía el testimonio de Plutarco. Su muerte al final de la primera temporada será uno de los detonantes que provoquen el inicio de la revuelta en el interior del ludus de Capua.

Alrededor de la escuela de gladiadores gira la trama de toda la primera temporada, en donde se entrecruzan las intrigas políticas con episodios que ilustran la formación de los luchadores, así como aventuras sentimentales y sexuales protagonizadas tanto por romanas como por esclavas. Estas últimas, aun siendo en la práctica simples objetos propiedad de sus diferentes dueños, manifiestan también, y en todo momento, ser las responsables de sus pasiones, deseos, cuerpos y sentimientos; romanas y esclavas sienten y disfrutan del mismo modo. Aunque son las mujeres romanas las que desarrollan un mayor grado de perversidad en sus juegos o intrigas.

En resumidas cuentas, ya tuvimos la oportunidad de comprobar cómo la información acerca de la presencia de mujeres en la revuelta de

65. Entre todas ellas podemos mencionar a Lucrecia, la esposa del lanista Batiato, y su amiga Gaia; Ilithia o Seppia, también entre las romanas, y dentro del grupo de las esclavas - al margen de Sura- estarían Melitta y Naevia, compañeras de otros líderes rebeldes. Mención aparte merecen los ejemplos de Aurelia y Laeta, mujeres romanas que por diversas vicisitudes acaban en el bando servil. 
Espartaco, tal y como aparece en las fuentes literarias grecorromanas, es muy parca. El testimonio de Plutarco informa acerca de una compañera del tracio —otros líderes rebeldes o simples participantes podían igualmente tener parejas-, a la que le otorga la categoría de sacerdotisa o, al menos, iniciada en los misterios dionisíacos; de ese modo, ya desde el inicio de los acontecimientos se le atribuye a Espartaco un destino brillante y, de paso, permite plantear la narración de la revuelta con unos ribetes trágicos. Pero en el relato ni tan siquiera aparece el nombre de la mujer y, además, ella no volverá a ser mencionada más adelante.

Al margen de la compañera del tracio, las escasísimas referencias a nuestra disposición hablan del grupo de esclavas que se apartan del campamento, por encontrarse en estado de impureza para realizar cultos religiosos, lo que les permite descubrir a un ejército romano. Un hecho casual que nos hace suponer que estamos ante un recurso narrativo que permite darle más agilidad al relato. La última alusión presente en los textos clásicos consigna el confuso episodio de los funerales en honor de una matrona romana, muerta durante la revuelta, conmemorados con la organización de unos combates de gladiadores.

Las recreaciones cinematográficas y televisivas de la revuelta, al carecer del hándicap de la fragmentación que encontramos en los testimonios literarios, les conceden a las mujeres un papel mucho más significativo en los acontecimientos. En las pantallas, como ya se atisbaba en los textos, la presencia femenina se divide entre las seguidoras del tracio y las romanas, en teoría enemigas, pero con las que, muy a menudo, mantiene Espartaco algún tipo de relación sentimental y sexual. Salvo contadas excepciones - vinculadas con la edad-, todas las mujeres que de un modo u otro rodean a Espartaco se caracterizan por desprender abundantes dosis de erotismo. Independientemente de si su vinculación con el gladiador sea duradera o mucho más efímera. Para las mujeres romanas suele ser Espartaco un simple capricho que satisfacer, mientras que con las serviles las relaciones son mucho más estables, compartiendo siempre planes de futuro, que se manifiestan en la presencia de niños o de lucha contra Roma que no cesa a pesar de la muerte de Espartaco.

\section{BiBLIOGRAFÍA}

Agustín de Hipona. La ciudad de Dios, edición de R. M. Marina Sáez. Madrid: Gredos, 2007.

Apiano. Historia Romana, edición de A. Sancho Royo. Madrid: Gredos, 1980. 
Cicerón. Discursos IV, edición de J. M. Baños Baños. Madrid: Gredos, 1994. Cicerón. Cartas, edición de M. Rodríguez-Pantoja. Madrid: Gredos, 1996. Cicerón. Filípicas, edición de J. C. Martín. Madrid: Cátedra, 2001.

Claudio Claudiano. De Bello Gothico, edición de G. Garuti. Bolonia: Patron Editore, 1979.

Diodoro de Sicilia. Biblioteca bistórica, edición de J. J. Torres Esbarranch. Madrid: Gredos, 2008.

Dionisio de Halicarnaso. Historia Antigua de Roma, edición de E. Jiménez y E. Sánchez. Madrid: Gredos, 1988.

Eutropio. Breviario, edición de E. Falque. Madrid: Gredos, 1999.

Frontino. Estratagemas, edición de A. García-Toraño. Madrid: Editorial Dykinson, 2019.

Gayo Salustio. Obras, edición de J. J. Martos Fernández. Madrid: Anaya, 2018.

Historia Augusta, edición de V. Picón y A. Cascón. Madrid: Akal, 1989.

Homero, Iliada, edición E. Crespo Güemes. Madrid: Gredos, 2000.

Horacio. Odas: canto secular, Épodos, edición de J. L. Moralejo. Madrid: Gredos, 2007.

Lucano. Farsalia, edición de D. Estefanía Álvarez. Madrid: Akal, 1989.

Paulo Orosio. Historias, edición de E. Sánchez Salor. Madrid: Gredos, 1982. Plutarco. Vidas Palalelas V, edición de J. Cano Cuenca. Madrid: Gredos, 2018.

Séneca. Consolaciones, edición de J. Mariné Isidro. Madrid: Gredos, 2019.

Sinesio de Cirene. Himnos. Tratados, edición de A. García Romero.

Madrid: Gredos, 1993.

Suetonio. Vida de los Césares, edición de V. Picón. Madrid: Cátedra, 2004.

Tito Livio. Periocas, edición de J. A. Villar Vidal. Madrid: Gredos, 1995.

Valerio Máximo. Hechos y dichos memorables, edición de S. López Moreda et al. Madrid: Gredos, 2003.

Baldi, Alfredo. Schermi proibiti. La censura in Italia 1947-1988. Venecia: B\&N, 2002.

Bernardini, Aldo. Il Cinema Muto Italiano. 1905-1909. Roma: B\&N, 1996.

Bernardini, Aldo y Vittorio Martinelli. Il Cinema Muto Italiano. 1913, 2. Roma: B\&N, 1994.

Bradley, Keith. Slavery and Rebellion in Roman world. 140-70 B. C. Indiana University Press, 1989.

Bonet Mójica, Lluis. Espartaco. Barcelona, Dirigido por..., 1997.

Capozza, María. "Spartaco e il sacrificio del caballo". Critica Storica II (1963): 251-293. 
Capozza, María. Movimenti servili nel mondo romano in etá republicana. I dal 501 al 184 CR. Roma: L'Erma, 1965.

Capozza, María. "La tradizione della guerra di Spartaco». Paideia XXXIII (1978): 7-25.

Chiti, Roberto. Dizionario dei registi del cinema muto italiano. Roma: MICS, 1997.

Cooper, Duncan L. «Who killed Spartacus?». Cineaste XVIII, 3 (1991): 18-27.

Cooper, Duncan L. "Dalton Trumbo VS Stanley Kubrick. Their debate over Arthur Koestler's The Gladiators». Cineaste XVIII, 3 (1991): 34-38.

De la Rosa, Cristina. "Esclavas y patricias en el cine de romanos: Spartacus de Kubrick». En Representación, construcción e interpretación de la imagen visual de las mujeres, editado por María Pilar Amador Carretero y María del Rosario Ruiz Franco, 35-55. Madrid: Editorial Archiviana, 2003.

Della Casa, Steve y Marco Giusti. Il grande libro di Ercole. Il cinema mitologico in Italia. Roma: CSC, 2013.

Douglas, Kirk. Yo soy Espartaco. Traducción de Ricardo García Pérez. Madrid: Capitán Swing, 2014.

Dumont, Hervé. L'Antiquité au Cinema. Vérités, Légendes et Manipulations. Paris: Nouveau Monde, 2009.

González, Antonio. "Le cinéma américain et l'Antiquité vue par Cecil B. De Mille et Stanley Kubrick». En Le Cinéma et ses objets, editado por Raphaëlle Costa de Beauregard et al., 303-314. Presses Universitaires de Rennes.

Guarino, Antonio. Spartaco. Analisi di un mito. Nápoles: Liguori Editore, 1979 .

Guarino, Antonio. «Spartaco professore?». Labeo XXVI (1980): 325-327.

Lapeña, Óscar. El mito de Espartaco: de Capua a Hollywood. Amsterdam: Hakkert, 2007.

Lapeña, Óscar. «Espartaco, el rebelde domesticado. Recepción cinematográfica y televisiva del gladiador tracio en el siglo XXI». Iberia 10 (2007): 153-180.

Lapeña, Óscar. «The stolen seduction: the image of Spartacus in Riccardo Freda's Spartaco gladiatore della Tracia». En Seduction \& Power. Antiquity in the visual performing arts, editado por Silke Knippschild y Marta García Morcillo, 171-182. Londres: Bloomsbury, 2013.

Lapeña, Óscar. «Spartacus (S. Kubrick, 1960); de la novela a la pantalla: génesis de Spartacus". Metakinema, n. ${ }^{\circ} 14$ (2014).

Lebedev, Nikolaj. Il Cinema muto sovietico. Torino: Einaudi, 1962. 
Martín Rodríguez, Antonio María. "De la historia al cine (pasando por la literatura): las mujeres de Espartaco». En Literatura y cine, editado por Germán Santana Henríquez, 179-246. Madrid: Ediciones Clásicas, 2012. Martinelli, Vittorio. "Espartaco (Spartaco, Enrico Vidali, 1913)». Nosferatu IV (1990): 64-65.

Masiello, Pasquale. "L'ideologia messianica e le rivolte servili». AFLB XI (1976): 179-196.

Matellano, Víctor, ed. Espartaco. Edición Especial 50 th. Madrid: T\&B Editores, 2009.

Matellano, Víctor, ed. Espartaco. El libro del 60 aniversario. Madrid: Notorius Ediciones, 2020.

Melo, Adrián. "Una plegaria para Andy Whitfield. Sobre homoerotismo e imaginarios sociales en la serie Spartacus: blood and sand». Representaciones vol. XIII, n. ${ }^{\circ} 2$ (2017): 1-16.

Orena, Roberto. Rivolta e rivoluzione. Il bellum di Spartaco nella crisi della repubblia e la riflessione storiografica moderna. Milán: Dott. A. Giuffré Editore,1984.

Posadas, Juan Luis. "La recluta ad tumultum como respuesta equivocada ante la rebelión de Espartaco en el año 73 a. C.». En XII Coloquio de la DIER. Poder central y poder local: dos realidades paralelas en la órbita política de Roma, editado por Gonzalo Bravo y Raúl González Salinero, 61-72. Salamanca: Signifer, 2015.

Prieto, Alberto. "Miedo, menosprecio y castigo a los esclavos en el cine de romanos". En Fear of slaves - Fear of Enslavement in the Ancient Mediterranean, 361-392. Université Franche-Comté, 2007.

Rubinsohn, Wolfgang Zeev. "Was the bellum spartacium a servile insurrection?». RIFC XCIX (1971): 290-299.

Russo, Luigi. «Lo Spartaco di R. Giovagnoli». Belfagor XI (1956): 74-79.

Sánchez León, María Luisa. Revueltas de esclavos en la crisis de la República. Madrid: Akal, 1991.

Schiavone, Aldo. Spartaco. Le arme e l'uomo. Torino: Einaudi, 2016.

Spartacus. Symposium rebus spartaci gestis dedicatum 2050 a. Éditions de L'Academie Bulgare des Sciences, Sofía 1981.

Strauss, Barry. La Guerra di Spartaco. Bari: Laterza, 2009.

Urbainczyk, Theresa. Spartaco. Bolonia: Il Mulino, 2015.

Wiedemann, Thomas. Emperors and gladiators. Londres: Routledge, 1992.

Winkler, Martin M. ed. Spartacus. Film and History. Oxford: Blackwell Publishing, 2007.

Wyke, María. Projecting the past. Ancient Rome, Cinema and History. London: Routledge, 1997. 